VOL. 3, NO. 1, Juni 2019

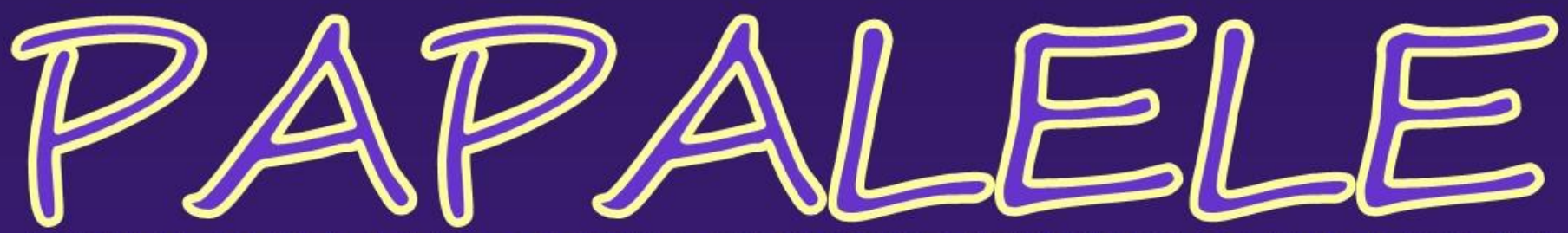
JURNAL PENELITIAN SOSIAL EKONOMI PERIKANAN DAN KELAUTAN

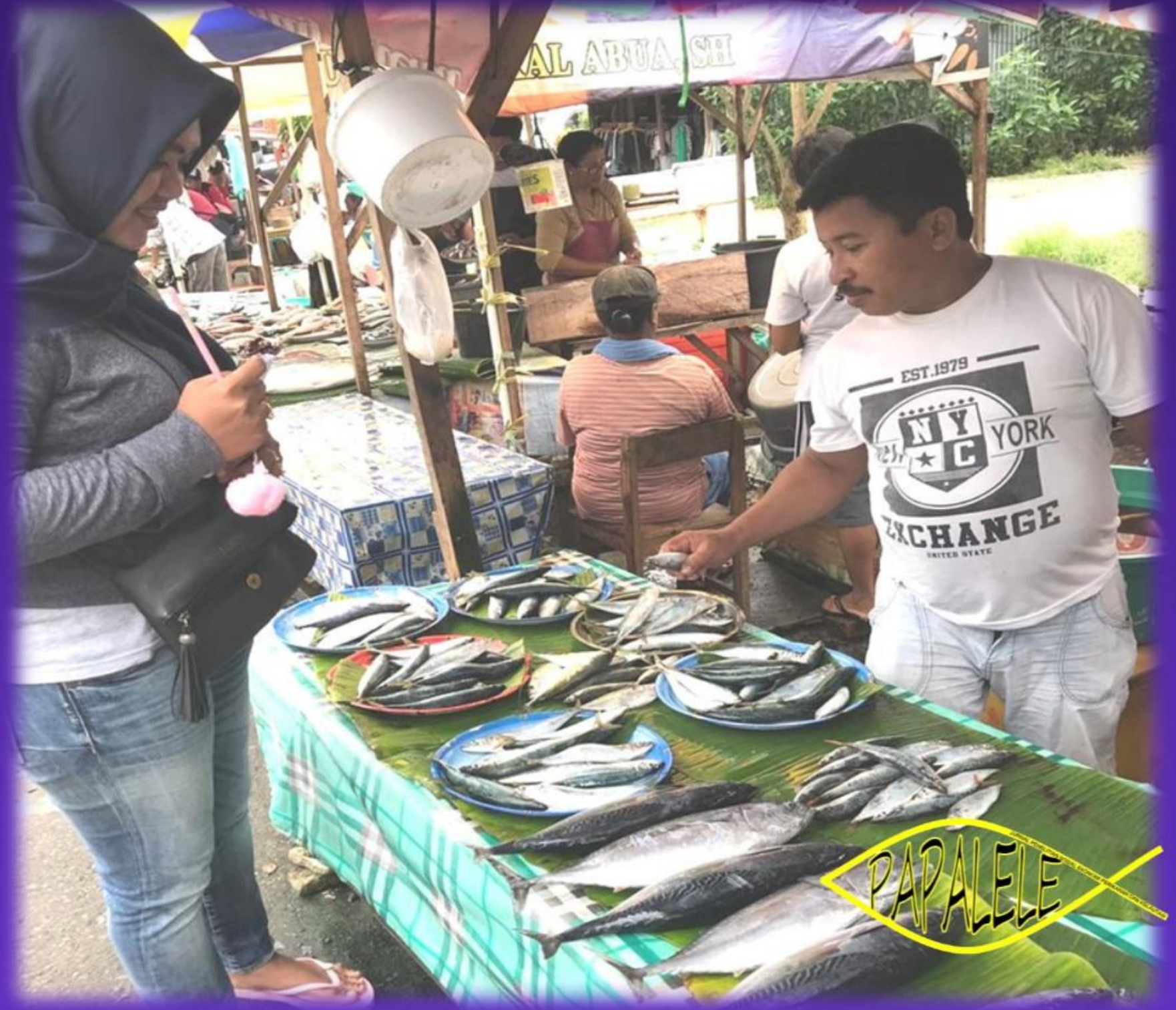

PAPALELE-JURNAL

PENELITIAN SOSIAL EKONOMI PERIKANAN DAN KELAUTAN
VOLUME 3

NOMOR
ISSN 2580-0787

Diterbitkan oleh:

का PROGRAM STUDI AGRIBISNIS PERIKANAN

ming FAKULTAS PERIKANAN DAN ILMU KELAUTAN 


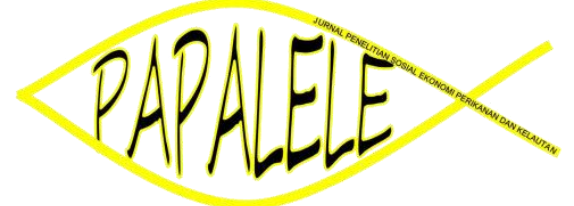

\section{JURNAL \\ PENELITIAN SOSIAL EKONOMI PERIKANAN DAN KELAUTAN}

\author{
PENANGGUNG JAWAB \\ Ketua Program Studi Sosial Ekonomi Perikanan \\ KETUA DEWAN REDAKSI \\ D. Bawole
}

RADAKTUR AHLI

V. Nikijuluw, M.S. Baskoro, J. Hiariej, F. Rieuwpassa, P. Wenno

REDAKTUR PELAKSANA

St. M. Siahainenia, R.L. Papilaya, Y. Lopulalan, Y.M.T.N. Apituley, V.J. Pical, W. Talakua, E. Talakua

PELAKSANA TATA USAHA

L.M. Soukotta, A. Ruban, K. Pattimukay, J. Sangaji, F. de Lima

PENERBIT

Program Studi Sosial Ekonomi Perikanan Jurusan Agrobisnis Perikanan

Fakultas Perikanan dan Ilmu Kelautan Universitas Pattimura

\section{ALAMAT REDAKTUR}

Program Studi Sosial Ekonomi Perikanan Jurusan Agrobisnis Perikanan Fakultas Perikanan dan Ilmu Kelautan Universitas Pattimura

Jln. Mr. Chr. Soplanit Poka-Ambon Telp. (0911) 379859. Fax 379196

PAPALELE merupakan jurnal penelitian ilmu sosial ekonomi perikanan dan kelautan yang menyajikan artikel tentang hasil penelitian yang berkaitan dengan bidang sosial ekonomi perikanan dan kelautan. Setiap naskah yang dikirim akan dinilai secara kritis oleh tim penilai yang relevan sebelum diterbitkan. Jurnal ini diterbitkan dua kali setahun, bulan Juni dan Desember. 


\section{KATA PENGANTAR}

Puji dan syukur kami panjatkan kepada Tuhan Yang Maha Esa atas rahmat-Nya. Jurnal PAPALELE, Jurnal penelitian Sosial Ekonomi Perikanan dan Kelautan kembali diterbitkan.

PAPALELE, Jurnal penelitian Sosial Ekonomi Perikanan dan Kelautan sesuai dengan Keputusan Lembaga Ilmu Pengetahuan Indonesia Nomor 0005.25800787/JI.3.1.SK.ISSN/2017.0529 Mei 2017 telah mengeluarkan nomor ISSN 2580-0787 untuk mulai penerbitan edisi volume 1 nomor 1, Juni 2017, dan sekarang melanjutkan perebitan untuk edisi volume 3 nomor 1, Juni 2019. Pada edisi ini, sama seperti edisi sebelumnya ditampilkan lima tulisan penelitian yang berkaitan dengan ilmu sosial ekonomi perikanan dan kelautan.

Dengan diterbitkannya jurnal ini, diharapkan dapat memberikan informasi ilmiah di bidang sosial ekonomi perikanan dan kelautan kepada pembaca. Saran dan masukan dari pembaca sangat diharapkan guna kesempurnaan penerbitan jurnal di waktu depan.

$\underline{\text { REDAKSI }}$ 


\section{DAFTAR ISI}

Halaman

KATA PENGANTAR

DAFTAR ISI ii

EFISIENSI TEKNIS DAN EKONOMI PERIKANAN TUNA HAND LINE DI NEGERI TIAL KABUPATEN MALUKU TENGAH

Oleh: Priscyllia Franetha Siahainenia, Dionisius Bawole, dan Willem Talakua $1-10$

ANALISIS KELAYAKAN USAHA KERAMBA JARING APUNG (KJA) DENGAN SISTEM MONOKULTUR DAN POLIKULTUR DI TANJUNG MARTHAFONS KOTA AMBON

Oleh: Tiffany Evangeline Leatemia

KELAYAKAN USAHA POLE AND LINE DI NEGERI HATIVE KECIL KOTA AMBON

Oleh: Ferdinan W. M. Haulussy

PRODUKTIVITAS DAN RESIKO USAHA PERIKANAN PURSE SEINE

DI NEGERI LATUHALAT

Oleh: Robert Frento Pattipeilohy dan Eygner Gerald Talakua

EFISIENSI DAN KEBERLANJUTAN USAHA PURSE SEINE DI KABUPATEN MALUKU TENGAH DAN KOTA AMBON

Oleh: Margie Wattimury 


\title{
KELAYAKAN USAHA POLE AND LINE DI NEGERI HATIVE KECIL KOTA AMBON
}

\section{FEASIBILITY OF THE POLE AND LINE BUSINESS IN HATIVE KECIL VILLAGE AMBON}

\author{
Ferdinan W. M. Haulussy \\ Program Studi Agrobisnis Perikanan, \\ Fakultas Perikanan dan Ilmu Kelautan, Universitas Pattimura \\ Diterima 29 Agustus 2019, disetujui 7 Oktober 2019
}

\begin{abstract}
ABSTRAK
Salah satu komoditas unggulan Provinsi Maluku adalah ikan cakalang (Katsuwonus pelamis) yang umumnya dihasilkan dengan alat tangkap pole and line. Usaha perikanan pole and line di Provinsi Maluku khususnya di Kota Ambon saat ini dihadapkan dengan permasalahan antara lain ketersediaan umpan hidup, daerah penangkapan semakin jauh yang akan berdampak pada trip penangkapan dan biaya operasional. Di samping itu usaha ini masih dikelola secara sederhana, walaupun biaya investasi dalam usaha ini cukup besar. Untuk itu penelitian ini bertujuan untuk menganalisis kelayakan usaha perikanan pole and line di Negeri Hative Kecil, Kota Ambon. Survei dilakukan terhadap 5 unit usaha pole and line untuk memperoleh data penelitian, Data yang diperoleh dianalisis dengan 4 kriteria investasi. Hasil penelitian menunjukkan bahwa, 1). Rata-rata biaya tetap yang dikeluarkan dari ke-5 unit usaha pole and line selama setahun sebesar Rp 80.566.238. Rata-rata biaya variabel yang dikeluarkan untuk ke-5 unit selama setahun sebesar Rp 272.571.200. Rata-rata penerimaan yang diperoleh ke-5 unit usaha pole and line sebesar Rp.878.034.000; dan 2). Kelima unit usaha pole and line di Negeri Hative Kecil layak untuk dikembangkan karena sesuai dengan kriteria penilaian kelayakan usaha dengan nilai NPV tertinggi pada unit 2 sebesar Rp 298.623.599 dan IRR sebesar 38,33\% dan nilai B/C sebesar 3,04 dengan payback period (PP) pada 1,17 tahun.
\end{abstract}

Kata kunci: pole and line, kelayakan, ikan cakalang, Hative Kecil

\section{ABSTRACT}

Skipjack (Katsuwonus pelamis) is a superior commodity of Maluku which is generally caught by pole and line. This pole and line business in Maluku, especially in Ambon is currently faced some problems including the availability of live bait, distant of fishing ground that have impact on fishing trips and operational costs. Even the investment of this business is quite large, but it is managed simply. This study aims to analyze the feasibility of pole and line fisheries business in Negeri Hative Kecil, Ambon. The survey was conducted on 5 pole and line business units and the data obtained were analyzed with 4 investment criterias. The results show that 1). The average fixed costs, variable costs and revenues of the 5 pole and line business units during the year amounted to $R p$ 80,566,238; Rp. 72,571,200 and Rp. 878,034,000; and 2). The five pole and line business units in Negeri Hative Kecil are feasible to be developed. The highest NPV value is the second unit, Rp 298,623,599; IRR 38.33\%; B/C value 3.04 with a payback period (PP) 1.17 years.

Key words: pole and line, feasibility, skip jack, Hative Kecil 


\section{PENDAHULUAN}

Salah satu komoditas unggulan Provinsi Maluku adalah ikan cakalang (Katsuwonus pelamis). Produksi ikan cakalang di perairan Maluku yang meliputi WPP-RI 714 (Laut Banda), 715 (Teluk Tomini, Laut Seram) dan 718 (Laut Arafura, Laut Timor). Produksi ikan cakalang tersebut umumnya dihasilkan dengan alat tangkap huhate (pole and line). Alat tangkap ini dikhususkan untuk menangkap ikan cakalang dan dianggap alat tangkap yang ramah lingkungan.

Kota Ambon merupakan salah satu wilayah yang memiliki armada penangkapan huhate (pole and line) yang cukup banyak. Daerah penangkapan alat tangkap ini berada pada WPP 714 dan WPP 715. Pada musim barat dilakukan pada perairan Seram Bagian Utara dan pada musim timur di Perairan Seram Bagian Timur sampai Perairan Laut Banda. Berdasarkan hasil survei di lapangan ditemukan fakta bahwa usaha perikanan pole and line di Kota Ambon saat ini dihadapkan dengan berbagai permasalahan antara lain ketersediaan umpan hidup, daerah penangkapan semakin jauh yang akan berdampak pada trip penangkapan dan biaya operasional. Di samping itu usaha ini masih dikelola secara sederhana, walaupun biaya investasi dalam usaha ini cukup besar.

Negeri Hative Kecil di Kecamatan Sirimau yang merupakan bagian dari Kota Ambon memiliki armada penangkapan huhate sebanyak 6 unit, namun yang masih beroperasi sebanyak 5 unit. Usaha ini sudah cukup lama dan berlangsung secara turun temurun. Dengan kondisi atau permasalahan yang dihadapi saat ini, apakah usaha ini masih menguntungkan? Oleh sebab itu penelitian ini dilakukan dengan judul "Kelayakan Usaha Perikanan Pole and line di Negeri Hative Kecil"

\section{METODE PENELITIAN \\ Metode Dasar Penelitian}

Metode yang digunakan dalam penelitian ini adalah survei. Sugiyono (2013) mengatakan bahwa survei adalah metode yang digunakan untuk mendapatkan data dari tempat tertentu yang alamiah (bukan buatan), tetapi peneliti melakukan perlakuan dalam pengumpulan data, misalnya dengan mengedarkan kuesioner, tes, wawancara terstruktur dan sebagainya.

\section{Metode Pengumpulan Data}

Data yang dikumpulkan dalam penelitian ini berupa data primer dan data sekunder. Data primer menurut Suharsimi (2013) adalah data yang dikumpulkan melalui pihak pertama, biasanya melalui wawancara atau jejak pendapat dan lain-lain. Data sekunder adalah data yang berhubungan dengan keadaan umum lokasi penelitian.

\section{Metode Pengambilan Sampel}

Populasi di dalam penelitian ini berjumlah 5 unit usaha pole and line di Negeri Hative Kecil. Pengambilan sampel yang digunakan adalah metode exhausting sampling, dimana jumlah sampel yang diambil sama dengan jumlah populasi.

\section{Metode Analisis Data}

Metode analisis data yang digunakan dalam penelitian ini adalah metode deskriptif kualitatif dan metode kuantitatif. Penelitian deskriptif kualitatif berusaha mendeskripsikan seluruh gejala atau keadaan yang ada, yaitu keadaan gejala menurut apa adanya pada saat penelitian dilakukan (Mukhtar, 2013). Metode deskriptif kualitatif digunakan untuk mendeskripsikan keadaan objek penelitian meliputi pengelolaan usaha pole and line. Sedangkan metode kuantitatif merupakan pengolahan data berbentuk angka (Sugiyono, 2013). Metode kuantitatif digunakan untuk menganalisis kelayakan usaha pole and line.

\section{Analisis Biaya}

Untuk menganalisis biaya - biaya yang dikeluarkan digunakan rumus total biaya (Ambarawati \& Artini, 2008) yang secara sistematis dapat dirumuskan sebagai berikut: $\mathrm{TC}=\mathrm{TVC}+\mathrm{TFC}$ dimana :

$\mathrm{TC}=$ Total Biaya (Total cost)

TVC $=$ Total Biaya Variabel (Total Variable Cost)

TFC = Total Biaya Tetap (Total Fixed cost $)$

\section{Analisis Penerimaan}

Penerimaan adalah perkalian antara output yang dihasilkan dengan harga jual 
(Soekartawi, 1995 dalam Zulkifli, 2012), secara sistematis dapat dirumuskan sebagai berikut: $\mathrm{TR}=\mathrm{P} \times \mathrm{Q}$ dimana :

$\mathrm{TR}=$ Total Penerimaan (Rp/Tahun)

$\mathrm{Q}=$ Jumlah Barang yang dijual (Rp/Tahun)

$\mathrm{P}=\operatorname{Harga}(\mathrm{Rp} / \mathrm{Tahun})$

\section{Analisis Pendapatan}

Untuk menganalisis pendapatan usaha pole and line digunakan analisis pendapatan yang menurut Talakua (1998) dalam Sarbia (2013), secara matematis dapat dirumuskan sebagai berikut:

$\mathrm{I}=\mathrm{TR}$

dimana:

I = Pendapatan usaha ( $\mathrm{Rp} /$ Tahun)

$\mathrm{TR}=$ Penerimaan $(\mathrm{Rp} / \mathrm{Tahun})$

\section{Sistem Bagi Hasil}

Pendapatan juragan adalah nelayan yang memiliki alat tangkap yang dioperasikan oleh orang lain (Mulyadi, 2009) yang dihitung berdasarkan pendapatan usaha dikurangi dengan sistem bagi hasil yang berlaku dan total biaya. Secara sistematis pendapatan juragan dirumuskan sebagai berikut :

$\mathrm{Ij}=\mathrm{I}-\mathrm{BHSL}-\mathrm{TC}$

dimana :

$\begin{aligned} \mathrm{Ij}= & \begin{array}{l}\text { Pendapatan Nelayan Pemilik } \\ (\text { Rp/Tahun })\end{array} \\ \mathrm{I}= & \begin{array}{l}\text { Pendapatan } \\ (\text { Rp/Tahun })\end{array} \\ \mathrm{BHSL}= & \text { Nilai Bagi Hasil (Rp/Tahun) } \\ \mathrm{TC}= & \text { Biaya Total (Rp/Tahun) }\end{aligned}$

Analisis Kelayakan Usaha

Ada beberapa kriteria investasi dalam menganalisis kelayakan usaha, antara lain sebagai berikut :

a. Payback Period (PP)

Payback Period adalah periode yang diperlukan untuk kembali dana yang telah dikeluarkan atau diinvestasikan (Sutrisno, 2009), yang dirumuskan sebagai:

$\mathrm{PP}=\frac{\text { Total Investasi }}{\text { Keuntungan }} \times 1$ tahun

Kriteria penilaian:

1) Apabila PP lebih cepat atau sama dengan umur ekonomis kapal, maka investasi layak dilanjutkan.
2) Apabila PP lebih lama dari umur ekonomis kapal, maka tidak layak dilanjutkan.

b. Benefit Cost Ratio $(\mathrm{B} / \mathrm{C})$

Benefit Cost Ratio, perbandingan antara present value dari net benefit positif dengan present value dari net benefit negatif (Umar, 2008), yang dapat dirumuskan sebagai berikut:

$$
\mathrm{B} / \mathrm{C}=\frac{\text { Hasil Penjualan }}{\text { Total Biaya }}
$$

Kriteria penilaian:

1) Bila Net B/C Ratio > 1, maka investasi layak dilakukan.

2) Bila Net B/C Ratio < 1, maka investasi tidak layak dilakukan.

c. Net Present Value (NPV)

Net Present Value adalah analisis keuangan yang digunakan untuk mengukur layak tidaknya suatu usaha dilakukan (Sunyoto, 2013). NPV dapat dirumuskan sebagai berikut:

NPV = Aliran Kas Bersih - Biaya Investasi Kriteria penilaian:

1) Jika NPV > 0, maka investasi layak dilakukan.

2) Jika NPV < 0, maka investasi tidak layak dilakukan.

\section{d. Internal Rate Of Return (IRR)}

Menurut Nurmalina dan Karyadi (2009), IRR dapat dirumuskan sebagai berikut:

$I R R=i+\frac{N P V^{\prime}}{N^{\prime} V^{\prime}-N^{\prime \prime}} \times\left(i^{\prime \prime}-i^{\prime}\right)$

dimana :

i' = merupakan nilai discount rate yang tertinggi yang masih memberi.

$\mathrm{NPV}^{\prime}=$ NPV yang positif.

I' = merupakan nilai discount rate terendah yang memberi.

NPV' = NPV yang negatif, sehingga diperoleh NPV sebesar nol.

Kriteria penilaian:

1) Jika IRR > tingkat bunga maka usulan proyek diterima.

2) Jika IRR < tingkat bunga usulan proyek ditolak. 


\section{HASIL DAN PEMBAHASAN \\ Pengelolaan Usaha Pole and Line di Negeri Hative Kecil}

Usaha perikanan tangkap pole and line yang terdapat pada Negeri Hative Kecil berjumlah lima unit dimana kelima unit tersebut hanya dimiliki satu pemilik saja. Usaha perikanan tangkap dengan alat tangkap pole and line dan sudah berjalan selama 25 tahun. Pemilik usaha memulai usahanya dengan modal sendiri dan hanya memiliki satu unit armada penangkapan yang kemudian terus berkembangan dengan cukup baik sehingga jumlah armadanya meningkat hingga berjumlah 5 unit, yaitu KM YORA1, KM YORA3, KM YORA4, KM YORA5 dan KM YORA6. Seluruh pengelolaan unit usaha pole and line diatur oleh pemilik.

Hasil penelitian menunjukkan bahwa pemilik usaha hanya sebagai pengawas terhadap setiap unit penangkapan karena biaya investasi, biaya tetap dan biaya variabel telah ditanggung pemilik sedangkan $\mathrm{ABK}$ bertugas untuk melakukan operasi penangkapan dan membantu dalam proses pemasaran hasil tangkapan. Dalam menjalankan usaha pole and line ada beberapa perencanaan yang sangat penting meliputi modal awal (barang investasi), tenaga kerja (ABK), jumlah trip, biaya-biaya yang akan dikeluarkan, serta penentuan wilayah penangkapan (fishing ground).

\section{Sumber daya Manusia}

Sumber daya manusia dalam konteks ini adalah tenaga kerja, termasuk pemilik dan anak buah kapal (ABK) yang melakukan kegiatan penangkapan di laut. Jumlah tenaga kerja dalam usaha perikanan pole and line dipengaruhi oleh ukuran kapal. Selain itu masing-masing tenaga kerja memiliki pembagian tugas sesuai dengan ketrampilan yang dimiliki, serta fungsi dan jabatannya sewaktu operasi penangkapan. Rata - rata ABK yang bekerja pada 5 usaha pole and line di Negeri Hative Kecil berjumlah 20 sampai 25 orang, dengan rincian: 1 orang nahkoda, $1 \mathrm{KKM} /$ masinis, 1 sampai 2 orang boy-boy, 1 orang koki dan 16 sampai 20 orang pemancing. Seluruh ABK tersebut berasal dari masyarakat Negeri Hative Kecil dan Desa Galala.

\section{Frekuensi, Musim dan Lokasi Penangkapan}

Frekuensi melaut usaha perikanan pole and line di Negeri Hative Kecil berlangsung kurang lebih 3-6 hari dengan waktu penangkapan dihitung dengan satuan per trip. Jumlah frekuensi melaut tergantung pada musim ikan dan musim kurang ikan dan juga ketersediaan modal dan tenaga kerja. Pada musim ikan rata-rata jumlah trip penangkapan per unit berkisar 2-4 trip/bulan, sedangkan pada musim kurang ikan berkisar 1-3 trip/bulan.

Hasil penelitian menunjukkan bahwa tangkapan tertinggi terjadi pada bulan Mei hingga September. Pada musim tangkapan ini operasi penangkapan ikan berlokasi pada Laut Banda sedangkan pada musim kurang ikan berlangsung dari November hingga April dan lokasi penangkapan di Laut Seram bagian utara dan Laut Buru.

Fasilitas Penangkapan dan Produksi Tangkapan Kapal motor pole and line yang digunakan nelayan pemilik dalam penelitian adalah jenis kapal yang terbuat dari fiberglass. Konstruksi kapal pole and line yang digunakan oleh ke 5 unit di Negeri Hative Kecil sama dengan konstruksi kapal pole and line yang pada umumnya terdiri dari ruang kemudi kapal, ruang tidur $\mathrm{ABK}$, ruang mesin, palka umpan hidup, ruang dapur, palka untuk menyimpan hasil tangkapan dan palka penyimpanan es.

Salah satu faktor penunjang aktivitas melaut adalah dimensi kapal pole and line. Ukuran kapal pole and line di Negeri Hative Kecil bervariasi, seperti pada Tabel 1. Tabel 1 menunjukkan bahwa umumnya bahan dasar kapal pole and line di Negeri Hative Kecil adalah fiberglass dan bermuatan 30 GT. Nilai produksi tangkapan usaha pole and line di Negeri Hative Kecil dapat dilihat pada Tabel 2. 
Tabel 1. Ukuran Kapal Pole and Line di Negeri Hative Kecil

\begin{tabular}{cccccc}
\hline Unit & Bahan & $\begin{array}{c}\text { Uanjang } \\
\text { (meter) }\end{array}$ & $\begin{array}{c}\text { Lebar } \\
\text { (meter) }\end{array}$ & Tinggi (meter) & \multirow{2}{*}{$\begin{array}{c}\text { Tonase } \\
\text { (GT) }\end{array}$} \\
\hline 1 & Fiberglass & 15,91 & 3,35 & 1,47 & 29 \\
2 & Fiberglass & 15,35 & 3,53 & 1,51 & 30 \\
3 & Fiberglass & 15,35 & 3,53 & 1,51 & 30 \\
4 & Fiberglass & 17,36 & 3,50 & 1,40 & 30 \\
5 & Fiberglass & 21,00 & 3,60 & 1,85 & 32 \\
\hline
\end{tabular}

Sumber: Data Primer Diolah, 2017

Tabel 2. Produksi Usaha Pole and Line di Negeri Hative Kecil

\begin{tabular}{cc}
\hline Unit & Nilai (Ton/Tahun) \\
\hline 1 & 76,659 \\
2 & 68,500 \\
3 & 47,658 \\
4 & 42,761 \\
5 & 57,100 \\
\hline Total & $\mathbf{2 9 2 , 6 7 8}$ \\
\hline Rata-Rata & $\mathbf{5 8 , 5 3 5}$ \\
\hline
\end{tabular}

Sumber: Data Primer Diolah, 2017

Berdasarkan data-data pada Tabel 2, dapat dilihat bahwa produksi masing-masing responden berbeda pada tahun 2017. Produksi tertinggi terdapat pada unit 1 yaitu sebanyak 76,659 ton/tahun dan yang paling rendah terdapat pada unit 4 sebanyak 42,761 ton/tahun. Rata-rata produksi dari kelima unit penangkapan pole and line sebanyak 58,535 ton/tahun.
Pemasaran Hasil Tangkapan

Pemasaran hasil tangkapan dilakukan langsung oleh pemilik, baik pada musim ikan maupun musim kurang ikan. Terdapat dua sasaran pasar penjualan yakni pada perusahaan seperti cold storage Aneka Sumber Tata Bahari (ASTB) dan Pasar Mardika. Biasanya pada musim ikan hasil tangkapan akan dijual di perusahaan dan pada musim kurang ikan akan dijual di pasar.

\section{Komponen Biaya}

Biaya Investasi

Tabel 3 memperlihatkan bahwa ratarata modal awal per unit pole and line di Negeri Hative Kecil adalah sebesar Rp.710.350.000 dan jenis barang modal dengan nilai investasi tertinggi adalah kapal dengan nilai Rp2.235.000.000 kemudian mesin utama sebesar Rp.1.147.200.000 dan kemudian yang paling terendah dari seluruh barang modal adalah alat pancing dengan nilai Rp.2.150.000.

Tabel 3. Rata-Rata Biaya Investasi Usaha Pole and Line di Negeri Hative Kecil

\begin{tabular}{cccr}
\hline No & Jenis Barang & Jumlah (Unit) & \multicolumn{1}{c}{ Nilai (Rp) } \\
\hline 1 & Kapal & 1 & 2.235 .000 .000 \\
2 & Mesin Utama & 1 & 1.147 .200 .000 \\
3 & Mesin Lampu & 1 & 22.940 .000 \\
4 & Pompa Sirkulasi & 1 & 61.700 .000 \\
5 & Lampu Kapal & 8 & 27.500 .000 \\
6 & Alat Navigasi & 1 & 28.260 .000 \\
7 & Alat Pancing & 25 & 2.150 .000 \\
\hline \multicolumn{4}{c}{ Total } \\
\hline Rata-rata
\end{tabular}

Sumber: Data Primer Diolah, 2017

Biaya Tetap

Biaya tetap yang dikeluarkan untuk usaha perikanan pole and line di Negeri Hative Kecil terdiri dari biaya penyusutan, biaya perbaikan dan perawatan, dan biaya administrasi yang dalam penelitian ini berupa pajak usaha per tahun dan SIUP. Biaya tetap tiap unit kapal dapat dilihat pada Tabel 4. 
Tabel 4. Biaya Tetap Usaha Pole and Line Di Negeri Hative Kecil

\begin{tabular}{crrrr}
\hline \multicolumn{5}{c}{ Biaya Tetap (Rp/Tahun) } \\
\hline Unit & Penyusutan & $\begin{array}{c}\text { Perbaikan dan } \\
\text { perawatan }\end{array}$ & Administrasi & $\begin{array}{c}\text { Jumlah Biaya } \\
\text { Tetap }\end{array}$ \\
\hline 1 & 50.128 .233 & 15.725 .000 & 7.500 .000 & 73.353 .233 \\
2 & 52.694 .333 & 18.220 .000 & 7.500 .000 & 78.414 .333 \\
3 & 52.684 .733 & 10.000 .000 & 7.500 .000 & 70.184 .733 \\
4 & 60.061 .667 & 10.000000 & 7.500 .000 & 77.561 .667 \\
5 & 72817.222 & 23.000 .000 & 7.500 .000 & 103.317 .222 \\
\hline Total & $\mathbf{2 8 8 . 3 8 6 . 1 8 9}$ & $\mathbf{7 6 . 9 4 5 . 0 0 0}$ & $\mathbf{3 7 . 5 0 0 . 0 0 0}$ & $\mathbf{4 0 2 . 8 3 1 . 1 8 9}$ \\
\hline Rata-Rata & $\mathbf{5 7 . 6 7 7 . 2 3 8}$ & $\mathbf{1 5 . 3 8 9 . 0 0 0}$ & $\mathbf{7 . 5 0 0 . 0 0 0}$ & $\mathbf{8 0 . 5 6 6 . 2 3 8}$ \\
\hline
\end{tabular}

Sumber: Data Primer Diolah, 2017

Dari Tabel 4 di atas terlihat bahwa ratarata biaya penyusutan ke-5 unit usaha pole and line di Negeri Hative Kecil selama setahun sebesar Rp.57.677.238, selama setahun ratarata biaya perbaikan dan perawatan sebesar Rp15.389.000 dan rata-rata biaya administrasi sebesar Rp.7.500.000 sehingga total jumlah rata-rata biaya tetap ke-5 unit usaha pole and line di Negeri Hative Kecil selama setahun sebesar Rp.80.566.238. biaya tetap yang paling tinggi terdapat pada unit 5 sebesar Rp.103.317.222 dan yang tersendah pada unit 3 sebesar Rp70.184.733 perbedaan ini dikarenakan terdapat perbedaan dimensi kapal sehingga biaya yang dikeluarkan juga tidak sama.

\begin{abstract}
Biaya Variabel
Tabel 5 menunjukkan bahwa biaya variabel tiap unit usaha pole and line berbedabeda. Hal ini disebabkan oleh jumlah trip tiap unit yang tidak sama yang turut memengaruhi kebutuhan BBM, oli, es, dan umpan. Dapat disimpulkan pada unit satu (1) total biaya variabel sebesar Rp.445.348.000 karena unit ini yang paling banyak melakukan operasi penangkapan selama satu tahun dan yang paling rendah pada unit empat (4) sebesar Rp.223.630.000 dan jumlah rata-rata biaya variabel ke-5 unit usaha pole and line di Negeri Hative Kecil sebesar Rp.292.571.200.
\end{abstract}

Tabel 5. Biaya Variabel Usaha Pole and Line di Negeri Hative Kecil

\begin{tabular}{cc}
\hline Unit & Biaya Variabel $(\mathbf{R p} / \mathbf{t a h u n})$ \\
\hline 1 & 445.348 .000 \\
2 & 321.050 .000 \\
3 & 241.155 .000 \\
4 & 223.630 .000 \\
5 & 231.673 .000 \\
\hline Total & $\mathbf{1 . 4 6 2 . 8 5 6 . 0 0 0}$ \\
\hline Rata-Rata & $\mathbf{2 9 2 . 5 7 1 . 2 0 0}$
\end{tabular}

Sumber: Data Primer Diolah, 2017

\section{Analisis Penerimaan dan Pendapatan Usaha Penerimaan Usaha}

Berdasasrkan hasil survei pada tempat penelitian harga jual ikan cakalang (Katsuwonus pelamis) pada perusahaan ASTB sebesar Rp.15.000/kg. dan pada pasar mardika sebesar Rp.450.000/loyang. Penerimaan usaha pole and line di Negeri Hative Kecil dapat dilihat pada Tabel 6 .
Berdasarkan data Tabel 6, terlihat bahwa penerimaan tertinggi terdapat pada unit satu (1) sebesar Rp.1.149.885.000/tahun karena unit ini yang paling banyak melakukan operasi penangkapan dan mempunyai produksi terbanyak. Total produksi ke-5 unit sebesar $292.678 \mathrm{~kg} /$ tahun dengan rata-rata $58.536 \mathrm{~kg} / \mathrm{tahun}$, sedangkan total penerimaan 
ke-5 unit sebesar Rp.4.390.170.000/tahun dengan rata-rata Rp.878.034.000,00/tahun.

\section{Pendapatan Usaha, Pemilik, dan ABK}

Pendapatan usaha diperoleh dari total penerimaan (total revenue) sedangkan pendapatan pemilik didapat dari total penerimaan (total revenue) dikurangi biaya total (total cost) . Sistem bagi hasil yang diterapkan dalam ke-5 usaha pole and line di Negeri Hative Kecil sebesar 75:25 dimana 75\% dari pendapatan merupakan bagian pemilik, dan sisanya $25 \%$ merupakan bagian dari ABK. Untuk lebih jelasnya dapat dilihat pada Tabel 7.

Tabel 6. Penerimaan Usaha Pole and Line di Negeri Hative Kecil

\begin{tabular}{cccc}
\hline Unit & Produksi $(\mathbf{k g} /$ tahun) & Harga $(\mathbf{R p} / \mathbf{k g})$ & Penerimaan $(\mathbf{R} /$ tahun $)$ \\
\hline 1 & 76.659 & 15.000 & 1.149 .885 .000 \\
2 & 68.500 & 15.000 & 1.027 .500 .000 \\
3 & 47.658 & 15.000 & 714.870 .000 \\
4 & 42.761 & 15.000 & 641.415 .000 \\
5 & 57.100 & 15.000 & 856.500 .000 \\
\hline Total & $\mathbf{2 9 2 . 6 7 8}$ & $\mathbf{7 5 . 0 0 0}$ & $\mathbf{4 . 3 9 0 . 1 7 0 . 0 0 0}$ \\
Rata-Rata & $\mathbf{5 8 . 5 3 6}$ & $\mathbf{1 5 . 0 0 0}$ & $\mathbf{8 7 8 . 0 3 4 . 0 0 0}$ \\
\hline
\end{tabular}

Sumber: Data Primer Diolah, 2017

Tabel 7. Pendapatan Usaha Pole and Line, Pemilik, dan ABK di Negeri Hative Kecil

\begin{tabular}{cccc}
\hline \multirow{2}{*}{ Unit } & \multicolumn{3}{c}{ Pendapatan/tahun (Rp) } \\
\cline { 2 - 4 } & Usaha & Pemilik & ABK \\
\hline I & 1.149 .885 .000 & 343.712 .517 & 287.471 .250 \\
II & 1.027 .500 .000 & 371.160 .667 & 256.875 .000 \\
III & 714.870 .000 & 224.812 .767 & 178.717 .500 \\
IV & 641.415 .000 & 179.869 .583 & 160.353 .750 \\
V & 856.500 .000 & 307.384 .778 & 214.125 .000 \\
\hline Total & $\mathbf{4 . 3 9 0 . 1 7 0 . 0 0 0}$ & $\mathbf{1 . 4 2 6 . 9 4 0 . 3 1 1}$ & $\mathbf{1 . 0 9 7 . 5 4 2 . 5 0 0}$ \\
Rata-Rata & $\mathbf{8 7 8 . 0 3 4 . 0 0 0}$ & $\mathbf{2 8 5 . 3 8 8 . 0 6 2}$ & $\mathbf{2 1 9 . 5 0 8 . 5 0 0}$ \\
\hline
\end{tabular}

Sumber: Data Primer Diolah, 2017

Berdasarkan Tabel 7, dapat dilihat bahwa nilai pendapatan masing-masing unit baik untuk usaha, pemilik, dan ABK. Hal ini disebabkan karena perbedaan jumlah hasil tangkapan dan juga banyaknya melakukan operasi penangkapan atau trip penangkapan selama setahun. Selain itu sistem bagi hasil juga merupakan kesepatan antara pemilik dan ABK. Pendapatan untuk tiap ABK dibagi menurut stratifikasi jabatan di atas kapal. Pendapatan ABK sesuai dengan stratifikasi untuk masingmasing unit dapat dilihat pada Tabel 8.

Tabel 8, menunjukkan hasil pembagian untuk masing-masing ABK pada ke-5 unit yang berbeda-beda karena tergantung pada pendapatan $\mathrm{ABK}$, jabatan, dan jumlah $\mathrm{ABK}$. Masing-masing unit memiliki satu orang nahkoda dan satu orang KKM dimana nahkoda dan KKM mendapatkan dua bagian dari total pendapatan ABK. Jumlah boy-boy pada unit 4 dan unit 5 berjumlah dua orang dan setiap boyboy mendapatkan 1,5 bagian dari pendapatan total ABK sedangkan jumlah koki pada ke-5 unit hanya satu orang dan mendapat 1,5 bagian dari total pendapatan ABK. Jumlah pemancing bervariasi mulai dari 16 orang pada unit 1,2, dan 3 kemudian 17 orang pada unit 4 dan 20 orang pada unit 5 . 
Tabel 8. Pendapatan ABK Masing-Masing Unit Usaha Pole and Line di Negeri Hative Kecil

\begin{tabular}{|c|c|c|c|c|c|}
\hline Unit & Jabatan & Jumlah (orang) & Bagian & Persentase(\%) & Nilai (Rp/tahun) \\
\hline \multirow{5}{*}{ I } & Nahkoda & 1 & 2 & 8,70 & 24.997 .500 \\
\hline & KKM & 1 & 2 & 8,70 & 24.997.500 \\
\hline & Boi-Boi & 1 & 1,5 & 6,52 & 18.748 .125 \\
\hline & Pemancing & 16 & $1 / 16$ & 69,57 & 199.980 .000 \\
\hline & Koki & 1 & 1,5 & 6,52 & 18.748 .125 \\
\hline \multicolumn{2}{|r|}{ Total } & 20 & 23 & 100 & 287.471 .250 \\
\hline Unit & Jabatan & Jumlah (orang) & Bagian & Persentase $(\%)$ & Nilai (Rp/tahun) \\
\hline \multirow{5}{*}{ II } & Nahkoda & 1 & 2 & 8,70 & 22.336 .956 \\
\hline & KKM & 1 & 2 & 8,70 & 22.336 .956 \\
\hline & Boi-Boi & 1 & 1,5 & 6,52 & 16.752 .717 \\
\hline & Pemancing & 16 & $1 / 16$ & 69,57 & 178.695 .652 \\
\hline & Koki & 1 & 1,5 & 6,52 & 16.752 .717 \\
\hline \multicolumn{2}{|r|}{ Total } & 20 & 23 & 100 & 256.875.000 \\
\hline Unit & Jabatan & Jumlah (orang) & Bagian & Persentase (\%) & Nilai (Rp/tahun) \\
\hline \multirow{5}{*}{ III } & Nahkoda & 1 & 2 & 8,70 & 15.540 .652 \\
\hline & KKM & 1 & 2 & 8,70 & 15.540 .652 \\
\hline & Boi-Boi & 1 & 1,5 & 6,52 & 11.655 .489 \\
\hline & Pemancing & 16 & $1 / 16$ & 69,57 & 124.325 .217 \\
\hline & Koki & 1 & 1,5 & 6,52 & 11.655 .489 \\
\hline \multicolumn{2}{|r|}{ Total } & 20 & 23 & 100 & 178.717 .500 \\
\hline Unit & Jabatan & Jumlah (orang) & Bagian & Persentase $(\%)$ & Nilai (Rp/tahun) \\
\hline \multirow{5}{*}{ IV } & Nahkoda & 1 & 2 & 8,33 & 13.362 .812 \\
\hline & KKM & 1 & 2 & 8,33 & 13.362 .812 \\
\hline & Boi-Boi & 2 & $1,5 / 3$ & 6,25 & 10.022 .109 \\
\hline & Pemancing & 17 & $1 / 17$ & 70,83 & 113.583 .906 \\
\hline & Koki & 1 & 1,5 & 6,25 & 10022.109 \\
\hline \multicolumn{2}{|r|}{ Total } & 22 & 24 & 100 & 160.353 .750 \\
\hline Unit & Jabatan & Jumlah (orang) & Bagian & Persentase(\%) & Nilai (Rp/tahun) \\
\hline \multirow{6}{*}{$\mathrm{V}$} & Nahkoda & 1 & 2 & 7,41 & 15.861 .111 \\
\hline & KKM & 1 & 2 & 7,41 & 15.861 .111 \\
\hline & Boi-Boi & 2 & $1,5 / 3$ & 5,56 & 11.895 .833 \\
\hline & Pemancing & 20 & $1 / 20$ & 74,07 & 158.611 .111 \\
\hline & Koki & 1 & 1,5 & 5,56 & 11.895 .833 \\
\hline & Total & 25 & 27 & 100 & 214.125 .000 \\
\hline
\end{tabular}

Sumber: Data Primer Diolah, 2017

\section{Kelayakan Usaha}

Terdapat empat metode yang biasa dipertimbangkan dalam penilaian aliran kas dari suatu investasi agar dapat mengukur nilai investasi mana yang layak untuk dikembangkan dari ke-5 unit usaha pole and line. Keempat metode yang digunakan dalam penelitian ini adalah Net Present Value (NPV), Internal Rate of Return (IRR), B/C Ratio, dan Payback Period $(P P)$. Hasil perhitungan kriteria investasi dari ke-5 unit usaha pole and line dapat dilihat pada Tabel 9.
Net Present Value (NPV)

Tabel 9 menunjukkan nilai NPV yang paling tinggi yaitu sebesar Rp.298.623.599 pada unit 2 yang mengindikasikan bahwa keuntungan sebesar Rp.298.623.599 dapat diperoleh pada unit 2 selama 5 tahun mendatang dan yang paling rendah sebesar Rp.185.203.655 pada unit 4 yang mengindikasikan keuntungan sebesar Rp.185.203.655 dapat diperoleh selama 5 tahun mendatang berdasarkan nilai waktu uang 
sekarang (present value of money), karena nilai NPV > 0, maka usaha dikatakan layak untuk dilanjutkan.

\section{Internal Rate of Return (IRR)}

Discount rate yang digunakan berdasarkan tingkat suku bunga pinjaman PT Bank Mandiri (Persero), sebesar $10 \%$ per tahun. Hasil analisis menunjukan bahwa tingkat diskonto IRR ke-5 unit usaha pole and line lebih besar dari social discount yaitu $10 \%$, dengan demikian keputusan berinvestasi pada usaha pole and line lebih menguntungkan dibanding jika dana tersebut disimpan di bank.

\section{Benefit Cost Ratio (B/C)}

Hasil penelitian menunjukan bahwa ke5 unit usaha pole and line di Negeri Hative Kecil memiliki nilai B/C yang menguntungkan dikarenakan nilai $\mathrm{B} / \mathrm{C}$ ke-5 unit usaha pole and line $>1$. Nilai $\mathrm{B} / \mathrm{C}$ tertinggi terdapat pada unit 2 yaitu sebesar 3,04 dan yang terendah adalah unit 4 yaitu sebesar 1,46.

\section{Payback Period (PP)}

Hasil penelitian menunjukan bahwa nilai PP yang paling baik dari ke-5 unit usaha pole and line di Negeri Hative Kecil terdapat pada unit 1 dengan nilai PP pada umur 0,96 tahun dari usaha pole and line ini mulai beroperasi. Dapat diartikan bahwa dalam jangka waktu 0,96 tahun usaha pole and line unit 1 sudah dapat membayar kembali semua biaya yang telah dikeluarkan. dan yang memiliki nilai PP paling lama yaitu pada unit 4 dengan nilai PP pada umur 2,34 tahun dari usaha pole and line mulai beroperasi.

Tabel 9. Analisis Kriteria Investasi Usaha Pole and Line di Negeri Hative Kecil

\begin{tabular}{ccccc}
\hline Unit & NPV(Rp) & IRR $(\%)$ & B/C Ratio & PP (Tahun) \\
\hline 1 & 211.363 .029 & 35,41 & 2,79 & 0,96 \\
2 & 298.623 .599 & 38,33 & 3,04 & 1,17 \\
3 & 185.916 .849 & 14,14 & 1,89 & 1,74 \\
4 & 185.203 .655 & 10,00 & 1,46 & 2,34 \\
5 & 247.614 .179 & 10,00 & 1,73 & 2,18 \\
\hline
\end{tabular}

Sumber: Data Primer Diolah, 2017

\section{KESIMPULAN}

1. Pemilik usaha pole and line di Negeri Hative Kecil sudah menjalankan usahanya cukup lama yaitu >25 tahun, perkembangannya cukup baik sehingga sampai sekarang usahanya mampu bertahan dan jumlah unit armada penangkapan meningkat dari satu unit menjadi lima unit. Sistem bagi hasil yang berlaku yaitu 75:25. Tenaga kerja (ABK) yang dibutuhkan sebanyak 20-25 orang untuk melakukan kegiatan penangkapan. Rata-rata biaya tetap yang dikeluarkan dari ke-5 unit usaha pole and line selama setahun sebesar Rp.80.566.238. Rata-rata biaya variabel yang dikeluarkan untuk ke-5 unit selama setahun sebesar Rp.272.571.200. Rata-rata penerimaan yang diperoleh ke-5 unit usaha pole and line di Negeri Hative Kecil sebesar Rp.878.034.000.

2. Kelima unit usaha pole and line di Negeri Hative Kecil layak untuk dikembangkan karena ke-5 unit usaha pole and line masih sesuai dengan kriteria penilaian kelayakan usaha dengan nilai NPV tertinggi pada unit 2 sebesar Rp.298.623.599 dan IRR sebesar $38,33 \%$ dan nilai $\mathrm{B} / \mathrm{C}$ sebesar 3,04 dengan payback period $(\mathrm{PP})$ pada 1,17 tahun.

\section{SARAN}

1. Kepada pemilik usaha pole and line di Negeri Hative Kecil untuk membuat pembukuan yang lebih lengkap tentang segala aspek finansial baik pengeluaran maupun pendapatan sehingga dapat mengontrol biaya-biaya yang dikeluarkan dan mengoreksi aspek finansial dalam usaha yang dijalankan sehingga pengelolaan usaha dapat berjalan dengan baik.

2. Pola sistem bagi harus diperbaiki agar dapat tercapai keseimbagan antara pendapatan pemilik dan pendapatan $\mathrm{ABK}$. 


\section{DAFTAR PUSTAKA}

Ambarawati, I. G. A. A dan Artini. W. 2008. Bahan Ajar Mata Kuliah Ekonomi Mikro. Universitas Udayana. Denpasar.

Mukhtar. 2013. Metode Penelitian Deskriftif Kualitatif. GP Press Group. Jakarta

Mulyadi. 2009. Akuntansi Biaya. STIE YKPN. Yogyakarta.

Sarbia. 2013. Analisis Penggunaan Input Terhadap Output serta Keuntungan dari Usaha Purse Seine di Negeri Hitumessing Kecamatan Leihitu. Skripsi Fakultas Perikanan dan Ilmu Kelautan Universitas Pattimura. Ambon Sugiyono. 2013. Metode Penelitian Kuantitatif, Kualitatif dan Kombinasi (mixed methods). ALFABETA. Bandung

Suharsimi, A. 2013. Prosedur Penelitian Suatu Pendekatan Praktek. Rineka Cipta. Jakarta.

Sunyoto. 2013. Ekonomi Manajerial (Konsep Terapan Bisnis). CAPS. Yogyakarta.

Sutrisno, E. 2009. Manajemen Sumber Daya Manusia. Kencana Prenada Media. Jakarta.

Zulkifli. 2012. Analisis Pendapatan dan Nilai Tambah pada Agroindustri Keripik Ubi di Kecamatan Tanah Luas Kabupaten Aceh Utara. Skripsi Fakultas Pertanian Universitas Malikussaleh. Aceh. 


\section{PEDOMAN PENULISAN}

\section{Pedoman Umum}

a. PAPALELE, Jurnal Penelitian Ilmu Sosial Ekonomi Perikanan dan Kelautan memuat hasil penelitian yang berkaitan dengan bidang sosial ekonomi perikanan dan kelautan.

b. Naskah yang dikirim merupakan karya asli dan belum pernah diterbitkan atau dipublikasikan.

c. Naskah diketik dalam bahasa Indonesia yang baik dan benar, tidak diperkenankan menggunakan singkatan yang tidak umum.

d. Naskah diketik pada kertas A4 dengan menggunakan program microsoft word dengan 2 spasi, margin 2.5 $\mathrm{cm}$ (kiri), $2 \mathrm{~cm}$ (atas), $2 \mathrm{~cm}$ (bawah) dan 1,5 cm (kanan), font 12 times new roman, setiap halaman diberi nomor secara berurutan dengan berkolom 1 (satu), dikirim beserta soft copy maksimal 15 halaman.

e. Naskah dikirim melalui alamat ke redaksi pelaksana PAPALELE, Jurnal Penelitian Ilmu Sosial Ekonomi Perikanan dan Kelautan, Program Studi Sosial Ekonomi Perikanan Jurusan Teknologi Hasil Perikanan, Fakultas Perikanan dan Ilmu Kelautan, Universitas Pattimura, Jln. Mr. Chr. Soplanit Poka-Ambon Telp. (0911) 379859, email: inseijurnal@gmail.com.

\section{Pedoman Penulisan Naskah}

a. Judul tidak lebih dari 15 kata dalam bahasa Indonesia dan bahasa Inggris.

b. Nama lengkap penulis tanpa gelar, penulis korespondensi disertai dengan alamat email.

c. Nama lembaga/institusi disertai alamat lengkap dengan kode pos.

d. Abstrak dalam bahasa Indonesia dan bahasa Inggris tidak lebih dari 200 kata.

e. Kata kunci dalam bahasa Inggris dan Indonesia maksimal 5 kata kunci ditulis dibawah abstrak

f. Pendahuluan, memuat latar belakang, perumusan masalah, keragka teoritis dan tujuan penelitian yang dibuat secara ringkas.

g. Metodologi, memuat lokasi dan waktu penelitian, bagaimana data diperoleh dan sumbernya, bagaimana metode analisis data, jika metode yang digunakan telah diketahui sebelumnya harus dicantumkan acuannya.

h. Hasil dan Pembahasan, memuat suatu topik atau permasalahan yang terkait dengan judul, didukung dengan tabel dan gambar yang dibahas secara komperhensif, dikomplementasikan dengan referensi primer yang mendukung, update dan advance.

i. Kesimpulan dan Saran, memuat pokok-pokok bahasan serta kemampuan mengartikulasi temuan pokok untuk saran yang diberikan.

j. Ucapan terima kasih (bila diperlukan).

k. Daftar Pustaka, dicantumkan dalam naskah bila ada pengutipan dari sumber lain. Proporsi daftar pustaka yang diacu yaitu $80 \%$ merupakan rujukan primer dan $80 \%$ merupakan terbitan 10 tahun terakhir. Disusun berdasarkan abjad, dan penulisan sesuai dengan peraturan yang sudah baku, misalnya:

[KKP] Kementerian Kelautan dan Perikanan. 2012. Statistik Perikanan Tangkap 2011. Direktorat Jenderal Perikanan Tangkap Kementerian Kelautan dan Perikanan

Bataglia P, Romeo T, Consoli P, Scottie G, and Andoloro F. 2010. Characterization of The Artisanal Fishery and Its Socio-Economic aspect in The Central Menditerranean Sea (Aeolian Islands, Italy). Fisheries Research $102: 87-9$.

Pingkan W, Hamzens S, dan Sumardjo. 2007. Strategi Inovasi Sosial Pengembangan Mutu Sumberdaya Manusia Nelayan. Jurnal Penyuluhan Volume 3 Nomor 1.

Fauzi A. dan Anna S. 2005. Pemodelan Sumberdaya Perikanan dan Kelautan. Untuk Analisis Kebijakan. PT. Gramedia Pustaka Utama. Jakarta.

Wibawa T. J, Novianto D, dan Nugroho B. 2012. Sebaran Spasial Kelimpahan Ikan Cakalang (Katsuwonus Pelamis) Berdasarkan Analisis Data Satelit Oseanografi. Prosiding InSINas, 29-30 Nopember 2012.

Muksin D. 2006. Optimalisasi Usaha Perikanan Cakalang (Katsuwonus pelamis) Di Kota Tidore Kepulauan Provinsi Maluku Utara. Tesis. Program Pascasarjana IPB. Bogor.

Syandri H. 2013. Nelayan Cerdas, Nelayan Mandiri. http://www.bunghatta.ac.id/ (diunduh pada 12 September 2013).

1. Tabel, diketik dalam bahasa Indonesia, diberi judul pada bagian atas tabel, diberi nomor urut (tidak dalam bentuk JPEG).

m. Gambar dan grafik, diketik dalam bahasa Indonesia, diberi judul singkat pada bagian gawah gambar dan diberi nomor urut. 
PROGRAM STUDI AGRIBISNIS PERIKANAN

FAKULTAS PERIKANAN DAN ILMU KELAUTAN

UNIVERSITAS PATTIMURA

Jln. Mr. Chr. Soplanit, Poka - Ambon, Maluku Telepon : (0911) 379859

E-mail : inseijurnal@gmail.com

Web : http://ojs.unpatti.ac.id./index.php/insei

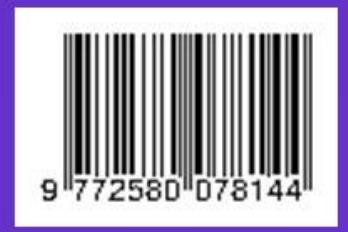

